\title{
Formulation and characterization of ketoprofen embedded polycaprolactone microspheres using solvent evaporation method
}

\author{
Pankaj Wagh, Jitendra Naik* \\ Department of Pharmaceutical Technology, University Institute of Chemical Technology, North Maharashtra \\ University, Jalgaon, 425 001, Maharashtra, India
}

*Corresponding Author: E-mail: jbnaik@nmu.ac.in; Tel: 91257 2258441; fax: +91257 2258403

Received: February 13, 2015; Revised: April 09, 2015; Published: July 01, 2015

\begin{abstract}
The purpose of this study was to prepare polymeric microspheres containing Ketoprofen (KFN) by single emulsion [oil-in-water $(o / w)$ ] solvent evaporation method. Polycaprolactone (PCL), biocompatible polymer, was used for the preparation of sustained released microspheres of KFN. A Plackett-Burman design was employed by using the Design-Expert ${ }^{\circledR}$ software (Version- 9.0.3.1, Stat-Ease Inc., Minneapolis, MN). Eleven factors out of six processing factors were investigated in order to enhance the encapsulation efficiency (EE) of the microspheres. The resultant microspheres were characterized for their size, morphology, EE, and drug release. Imaging of particles was performed by field emission scanning electron microscopy. Interaction between the drug and polymers were investigated by Fourier transform infrared (FTIR) spectroscopy, X-ray powder diffractometry (XRPD) and Differential Scanning Calorimetry (DSC). Graphical and mathematical analyses of the design showed that concentration of factor $P C L(B)$ and varying speed $(F$, revolution per minute, rpm) were significant negative effect on the EE and identified as the significant factor determining the EE of the microspheres. The microspheres showed high \% EE (31.18\% to $96.81 \%)$. The microspheres were found to be discrete, oval with porous surface. The FTIR analysis confirmed no interaction of KFN with the polymer. The XRPD revealed the dispersion of drug within microspheres formulation. Sustained drug release profile over $12 \mathrm{~h}$ was achieved by PCL polymer. In conclusion, polymeric microspheres containing KFN can be successfully prepared using the technique of experimental design, and these results helped in finding the optimum formulation variables for EE of microspheres.
\end{abstract}

\section{Keywords}

Plackett-Burman design, Encapsulation efficiency, Sustained release

\section{Introduction}

Microspheres are well accepted system to control the drug release from the dosage form to improve bioavailability; it reduces absorption difference in patients, and dosing frequency as well as adverse effects during prolonged treatment [1]. Ketoprofen (KFN) is an NSAID having prominent anti-inflammatory, analgesic and antipyretic properties. KFN is an arylpropionic acid derivative and it is one of the most powerful inhibitors of cyclooxygenase at concentrations well within the range of therapeutic plasma concentration $(E C 502 \mu \mathrm{g} / \mathrm{I})$, which is resulting in a reduction in the tissue production of prostaglandins such as PGE2 and PGF2a [2]. In addition to its effect on cyclooxygenase, KFN inhibits the lipoxygenase pathway 
of the arachidonic acid cascade. KFN is also a strongest inhibitor of bradykinin, an important chemical mediator of pain and inflammation. It also stabilizes lysosomal membranes against osmotic change and prevents the release of lysosomal enzymes that mediate tissue destruction in inflammatory react ions [3]. The half-life of KFN in plasma is about 2-2.5 hours. Due to its short half-life, KFN is a very good candidate for the formulation of sustained release dosage forms [2-3]. It is BCS II drug [4], KFN has low water solubility and exposure to the stomach at high levels can cause severe gastric damage such as ulceration or bleeding. To overcome these disadvantages, sustained release dosage forms have been developed, resulting in less frequent dosing and less GI disturbances [5].

The solvent evaporation technique which was used in this study is a simple process that is also inexpensive enough for scaling up to a commercial level. The purpose of the present study was to prepare KFN microspheres by using solvent evaporation method and to study the effect of drug-polymer concentration on drug release. The main objective of this work was to investigate the possibility of getting sustained release KFN microspheres by the solvent evaporation method using polycaprolactone (PCL). Investigation of the effect of various processing and formulation factors such as drug to polymer ratio, stirring speed, surfactant concentration and others on the, yield, encapsulation efficiency (EE), and in-vitro release rate of drug from the microspheres were performed.

\section{Materials and Methods}

\section{Materials}

Ketoprofen (KFN) was procured from Swapnroop Drugs and Pharmaceuticals (Aurangabad, India). Polycaprolactone (PCL- mw 70,000) was purchased from Sigma - Aldrich Chemicals India Pvt. Ltd. (Mumbai, India). n-Hexane and Dichloromethane (DCM) was procured from Merck Specialities Pvt. Ltd. (Mumbai, India). Polyvinyl alcohol (PVA- Mw 140, 000) was procured from HiMedia Laboratories Pvt. Ltd. (Mumbai, India). All other solvents and reagents were of analytical grade and used as provided.

\section{Methods}

\section{Plackett-Burman design (PBD)}

The PBD factorial design of experiment was performed using Design-Expert ${ }^{\circledR}$ (DoE) software (Version9.0.3.1, Stat-Ease Inc., Minneapolis, MN) [6-10]. In PBD, eleven numbers of lowest factors and forty seven numbers of highest factors can be used. In lowest eleven factors, five formulation factors and one process factor was investigated in order to enhance the $E E$ of the microspheres and remaining five factors was dummied. PBD plotted twelve runs containing variation value of factors. Six independent variables such as amount of KFN drug (A, mg), PCL (B, mg), DCM (C, ml), Water (D, ml), Surfactant $(E, \% \mathrm{w} / \mathrm{v})$ and Speed $(F$, revolution per minute, rpm). The level of screening variables evaluated in this study is listed in Table 1 . DoE analyses the input data, presents the rank ordering of the variables, and designates the sign to the effect to indicate whether an increase in factor value was advantageous or not [11-13]. DoE shows, formulation equations, ANOVA for EE and drug loading (DL), p-value, F-value, mean square and $\mathrm{R}^{2}$ value. It also shows Pareto chart, experimental, predicted, and \% prediction error values. The significance of the design was determined by the comparisons of statistical parameters, and on the basis of higher values of $\mathrm{R}^{2}$. Twodimensional (2D) contour plots and three-dimensional (3D) response plots resulting from the equations were constructed using Design- Expert ${ }^{\circledR}$ software. 
Table 1. Screening variables and their levels in the Plackett-Burman Design

\begin{tabular}{|c|c|c|c|c|}
\hline Factor & Name & Unit & Low Actual & High Actual \\
\hline A & KETOPROFEN & $\mathrm{mg}$ & 100 & 200 \\
\hline B & PCL & $\mathrm{mg}$ & 100 & 400 \\
\hline C & DCM & $\mathrm{ml}$ & 20 & 30 \\
\hline D & WATER & $\mathrm{ml}$ & 70 & 100 \\
\hline E & PVA & $\mathrm{mg}$ & 0.1 & 0.3 \\
\hline F & SPEED & $\mathrm{rpm}$ & 700 & 1000 \\
\hline G & G & - & -1 & 1 \\
\hline H & H & - & -1 & 1 \\
\hline J & $\mathrm{J}$ & - & -1 & 1 \\
\hline K & $\mathrm{K}$ & - & -1 & 1 \\
\hline L & L & - & -1 & 1 \\
\hline
\end{tabular}

\section{Preparation of encapsulated microspheres}

KFN loaded microspheres were prepared using oil-in-water (O/W) single emulsion solvent evaporation method. An accurate weighed quantity of A (KFN), B (PCL) was mixed with a C (DCM) organic solvent as per the design. The resulting oil phase was injected drop wise using a syringe with a $21.5 \mathrm{G}$ needle into a factor $\mathrm{D}$ (distilled water) as an external phase with stirring speed 700/1000 rpm using lab stirrer (Remi electrotechnik limited, Thane, India) in a room temperature containing varying concentrations of PVA (factor $E$ ) as an emulsifier to produce an $\mathrm{O} / \mathrm{W}$ single emulsion. After $60 \mathrm{~min}$, $\mathrm{n}$-hexane was added into the solution for hardening of the microspheres. Fig. 1 shows the schematic representation of formulation of KFN microspheres. Stirring was continued further at a varying speed 700/1000 rpm until the evaporation of organic solvent from solid microspheres. The microsphere were collected by filtration using vacuum filtration (Tid -15 , Temp. $55^{\circ} \mathrm{C}$, Speed $1440 \mathrm{rpm}$ ) washed with $\mathrm{n}$-Hexane, air dried for $48 \mathrm{~h}$ in room temperature and was used for further studies $[6,14]$.

\section{Characterization of the microspheres}

\section{Encapsulation efficiency (\% EE)}

The amount of KFN encapsulated into microsphere was determined by UV-vis spectrophotometer (HITACHI U-2900, Tokyo, Japan). An accurately weighed $10 \mathrm{mg}$ of microspheres were stirred with dichloromethane $(5 \mathrm{ml})$ to dissolve the polymer as well as drug and extracted in phosphate buffer solution pH 6.8 (up to $100 \mathrm{ml}$ ). Stirring was continued for $30 \mathrm{~min}$ at room temperature to facilitate the evaporation of organic solvent. The dispersion was filtered, and the residue was washed with phosphate buffer solution. The drug content was determined in the filtrate after appropriate dilution with a phosphate buffer solution at $260 \mathrm{~nm}$ using UV-vis spectrophotometer. The EE was expressed as the percentage of drug incorporated in the formulation relative to the total amount of drug (theoretical quantity) used in the formulation [6]. The \% EE of KFN was calculated using the following equations:

Drug entrapment efficiency $(\%)=$ (actual drug content/theoretical drug content $) \times 100$ 


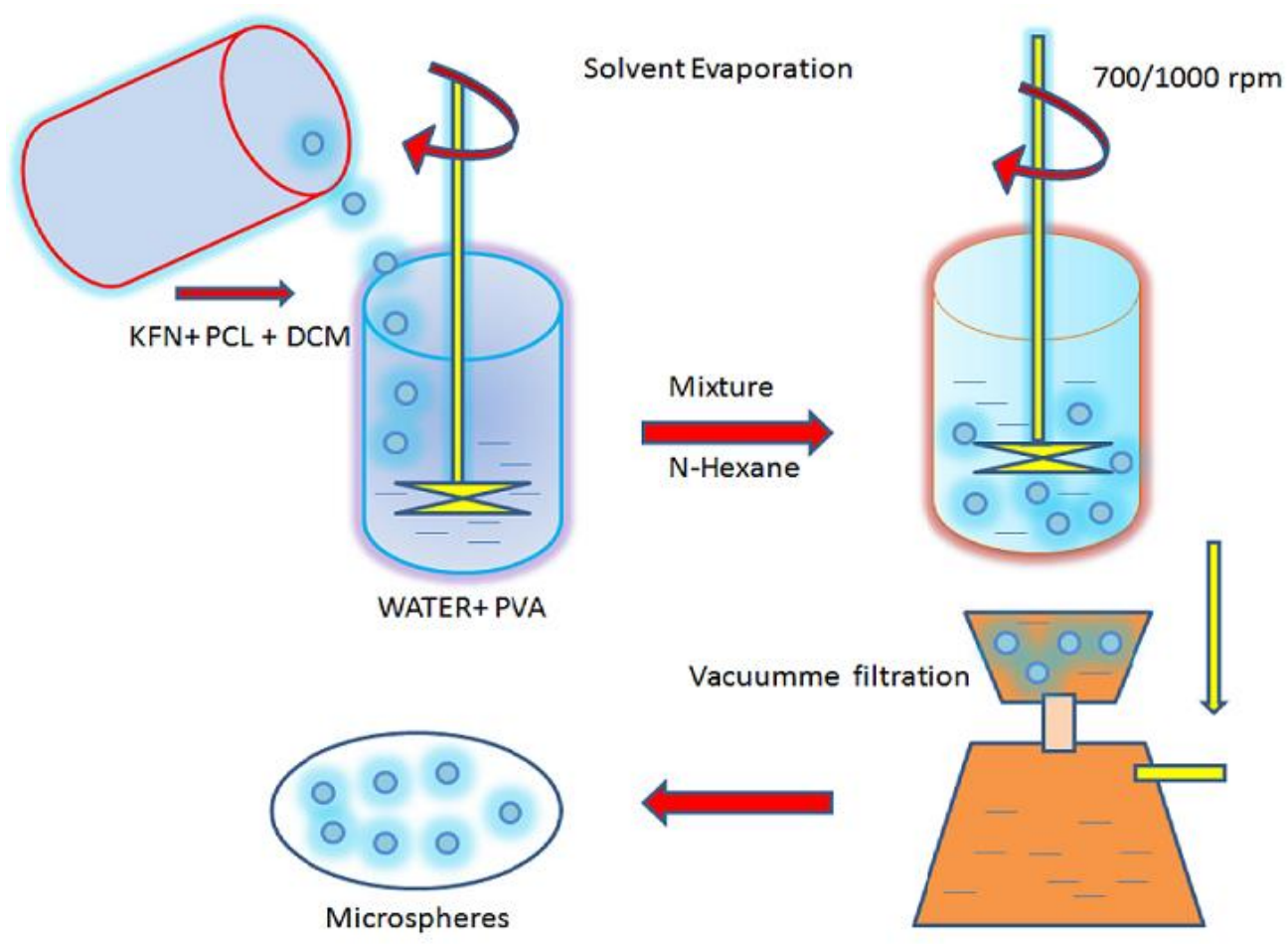

Figure 1. Schematic representation of formulation of KFN microspheres

Among all twelve run formulations of microspheres having higher encapsulation efficiency were chosen for further characterization study.

\section{$\underline{\text { Scanning electron microscopy }}$}

The morphology of microspheres was investigated by scanning electron microscopy (FESEM-S 4800, Hitachi, Japan) at a working distance of $8.0-8.9 \mathrm{~mm}$ and accelerating voltage of $15.0 \mathrm{kV}$. The particles were examined for shape, size and surface characteristics. For the morphology study, microsphere were mounted on metal stub using double sided adhesive tape and coated with gold for 80 second under vacuum.

\section{Fourier Transform Infrared (FTIR) spectroscopy study}

The chemical structure of the KFN, PCL and drug loaded microspheres were analysed using FTIR spectrophotometer (FTIR-8400, Shimadzu, Asia Pacific Pvt. Ltd. Singapore) by KBr pellet method. Sample (1 $\mathrm{mg}$ ) was mixed with $\mathrm{KBr}(40 \mathrm{mg})$ and formed into a disk by applying force in a manual press. Spectra were recorded in the scan range of $4000-400 \mathrm{~cm}^{-1}$.

\section{$\underline{X-\text { ray diffraction }(\mathrm{XRD})}$}

X-ray diffraction patterns of $\mathrm{KFN}, \mathrm{PCL}$ and drug loaded microspheres were obtained in X-ray diffractometer (Bruker, D8 Advanced, Germany) with $\mathrm{Cu} K \alpha$ radiation $(\lambda=1.5406$ Á). The samples were analysed over the angle range $(2 \theta) 10^{\circ}-80^{\circ}$.

\section{Differential scanning calorimetriy(DSC)}

Thermal behaviour of the sample KFN, PCL and drug loaded microsphere was determined by Differential Scanning Calorimetric (DSC-60, Shimadzu). Accurately weighed samples (5-10 mg) were sealed in an 
aluminium pan and scanned at a temperature range of $30{ }^{\circ} \mathrm{C}$ to $400{ }^{\circ} \mathrm{C}$ at the rate of $10{ }^{\circ} \mathrm{C} / \mathrm{min}$ under dry nitrogen atmosphere purge of $50 \mathrm{~mL} / \mathrm{min}$.

\section{$\underline{\text { In vitro drug dissolution studies }}$}

Drug release from microspheres was performed in vitro using phosphate buffer $(\mathrm{pH}$ 6.8) for $12 \mathrm{~h}$ in Dissolution test App. (model FC 6X12R Electrolab TDT - 08 L, India) USPXXVIII, type-I with speed $100 \mathrm{rpm}$ and temperature $37 \pm 0.5^{\circ} \mathrm{C}$. The dissolution medium of phosphate buffer $(\mathrm{pH} 6.8)$ was prepared according to Indian Pharmacopoeia 2007 [15]. From $900 \mathrm{ml}$ phosphate buffer i.e. dissolution medium $10 \mathrm{ml}$ were withdrawn at predetermined time intervals and replenished with same volume of fresh dissolution media to maintain the sink condition. The samples were filtered through a Whatman filter paper no. 41. The KFN content of each sample after suitable dilution was assayed by UV spectroscopy at $\lambda$ max of $260 \mathrm{~nm}$ using a $1 \mathrm{~cm}$ cell.

\section{Result and Discussion}

\section{Statistical design and analysis}

The PBD is an efficient approach to evaluate the results which are shown in Table 2. Design shows the formulation equation of $\% \mathrm{EE}$ can be represented by the following equation:

$$
\mathrm{EE}=+84.08-0.051 \mathrm{~A}-3.02 \mathrm{~B}+5.15 \mathrm{C}+7.34 \mathrm{D}+6.01 \mathrm{E}-2.85 \mathrm{~F}-8.57 \mathrm{G}-7.71 \mathrm{H}+1.64 \mathrm{~J}-6.21 \mathrm{~L}
$$

Table 2. The Plackett-Burman Experimental Design matrix (in coded level) and experimental results

\begin{tabular}{|c|c|c|c|c|c|c|c|c|c|c|c|c|}
\hline Runs & \multicolumn{10}{|c|}{ Variables } \\
\hline & A & B & C & D & E & F & G & H & J & K & L & EE, \% \\
\hline 1 & 1 & -1 & 1 & -1 & -1 & -1 & 1 & 1 & 1 & -1 & 1 & $65.31 \pm 0.56$ \\
\hline 2 & -1 & 1 & 1 & 1 & -1 & 1 & 1 & -1 & 1 & -1 & -1 & $96.81 \pm 1.59$ \\
\hline 3 & -1 & -1 & 1 & -1 & 1 & -1 & 1 & 1 & -1 & 1 & -1 & $91.86 \pm 2.74$ \\
\hline 4 & 1 & -1 & -1 & -1 & 1 & -1 & 1 & -1 & 1 & 1 & -1 & $95.04 \pm 2.12$ \\
\hline 5 & -1 & 1 & -1 & -1 & -1 & 1 & 1 & 1 & -1 & 1 & 1 & $96.20 \pm 1.25$ \\
\hline 6 & -1 & -1 & -1 & -1 & 1 & 1 & -1 & 1 & 1 & -1 & 1 & $87.79 \pm 2.55$ \\
\hline 7 & 1 & 1 & 1 & -1 & 1 & 1 & -1 & 1 & -1 & -1 & -1 & $94.66 \pm 0.57$ \\
\hline 8 & 1 & 1 & -1 & -1 & 1 & -1 & 1 & -1 & -1 & -1 & 1 & $80.27 \pm 2.43$ \\
\hline 9 & 1 & 1 & -1 & -1 & -1 & -1 & -1 & 1 & 1 & 1 & -1 & $93.24 \pm 1.86$ \\
\hline 10 & -1 & 1 & 1 & -1 & 1 & -1 & -1 & -1 & 1 & 1 & 1 & $31.18 \pm 0.94$ \\
\hline 11 & -1 & -1 & -1 & -1 & -1 & -1 & -1 & -1 & -1 & -1 & -1 & $92.34 \pm 0.83$ \\
\hline 12 & 1 & -1 & 1 & -1 & -1 & 1 & -1 & 1 & -1 & 1 & 1 & $84.31 \pm 2.24$ \\
\hline
\end{tabular}

From the above equation it is observed that the EE increased by the water (D), PVA (E), and followed by the dummy factors; $(G),(H),(L)$. Dummy factors $(G)$ and $(H)$ have higher and significant effects on EE in the microspheres preparation process. Table 3 shows the design of ANOVA for encapsulation efficiency, $\mathrm{p}$-value, F-value, mean square and $\mathrm{R}^{2}$ of the model. From the 
ANOVA of PBD for drug loading, $p$-value, F-value, mean square and $\mathrm{R}^{2}$ of the model are given in the Table 4. Standardized Pareto chart of EE is shown in Fig. 2A and DL in Fig. 2B. Pareto charts showed that the parametrical graph containing the t-value of the student's t-test represents bars with a length proportional to the absolute value of the estimated effects divided by the standard error. There are eleven factors in which water (factor D), PVA (factor E) and Dummy factor G (Unknown in the process) has a significant influence on the $\mathrm{EE}$.

Table 3. Analysis of Variance for Encapsulation Efficiency (EE)

\begin{tabular}{|c|c|c|c|c|c|}
\hline Source & $\begin{array}{l}\text { Sum of } \\
\text { Squares }\end{array}$ & d.f. & $\begin{array}{c}\text { Mean } \\
\text { Squares }\end{array}$ & $\begin{array}{c}F \\
\text { value }\end{array}$ & $\begin{array}{l}\text { p-value } \\
\text { Prob }>F\end{array}$ \\
\hline Model & 3695.00 & 101 & 369.50 & 1.55 & 0.5589 (NS) \\
\hline$A$ & 0.031 & 1 & 0.031 & 1.30 & 0.9927 \\
\hline$B$ & 109.51 & 1 & 109.51 & 0.46 & 0.6204 \\
\hline$C$ & 318.37 & 1 & 318.37 & 1.34 & 0.4537 \\
\hline $\mathrm{D}$ & 646.36 & 1 & 646.36 & 2.72 & 0.3471 \\
\hline$E$ & 432.84 & 1 & 432.84 & 1.82 & 0.4060 \\
\hline $\mathrm{F}$ & 97.41 & 1 & 97.41 & 0.41 & 0.6375 \\
\hline $\mathrm{G}$ & 881.17 & 1 & 881.17 & 3.71 & 0.3050 \\
\hline $\mathrm{H}$ & 713.48 & 1 & 713.48 & 3.00 & 0.3333 \\
\hline $\mathrm{J}$ & 32.44 & 1 & 32.44 & 0.14 & 0.7747 \\
\hline $\mathrm{L}$ & 463.39 & 1 & 463.39 & 1.95 & 0.3957 \\
\hline Residual & 237.72 & 1 & 237.72 & - & - \\
\hline Cor Total & 3932.72 & 11 & - & - & - \\
\hline
\end{tabular}

d.f. = degree of freedom, $S=$ significant, $N S=$ non-significant .

Standard deviation of the residual $=15.42$. Correlation coefficient $=0.9396$.

Table 4. Analysis of Variance for Drug loading (DL).

\begin{tabular}{|c|c|c|c|c|c|}
\hline Source & $\begin{array}{c}\text { Sum of } \\
\text { Squares }\end{array}$ & d.f. & $\begin{array}{c}\text { Mean } \\
\text { Squares }\end{array}$ & $\begin{array}{c}\mathbf{F} \\
\text { value }\end{array}$ & $\begin{array}{c}\text { p-value } \\
\text { Prob>F }\end{array}$ \\
\hline Model & 5554.80 & 10 & 555.48 & 152.10 & $0.0630(\mathrm{NS})$ \\
\hline A & 978.85 & 1 & 978.85 & 268.03 & $0.03889(\mathrm{~S})$ \\
\hline B & 872.11 & 1 & 872.11 & 238.80 & $0.0411(\mathrm{~S})$ \\
\hline C & 84.48 & 1 & 84.48 & 23.13 & 0.1305 \\
\hline D & 760.98 & 1 & 760.98 & 208.37 & $0.0440(\mathrm{~S})$ \\
\hline E & 152.08 & 1 & 152.08 & 41.64 & 0.0979 \\
\hline F & 438.26 & 1 & 438.26 & 120.01 & 0.0580 \\
\hline G & 673.50 & 1 & 673.50 & 184.42 & $0.0468(\mathrm{~S})$ \\
\hline H & 24.25 & 1 & 24.25 & 6.64 & 0.2356 \\
\hline J & 1282.16 & 1 & 1282.16 & 351.08 & $0.0339(\mathrm{~S})$ \\
\hline L & 288.12 & 1 & 288.12 & 78.89 & 0.0714 \\
\hline Residual & 3.65 & 1 & 3.65 & - & - \\
\hline Cor Total & 5558.45 & 11 & - & - & - \\
\hline
\end{tabular}

d.f. = degree of freedom, $S=$ significant, $N S=$ non-significant.

Standard deviation of the residual $=1.91$. Correlation coefficient $=0.9993$. 


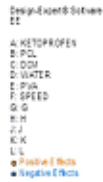

(A)
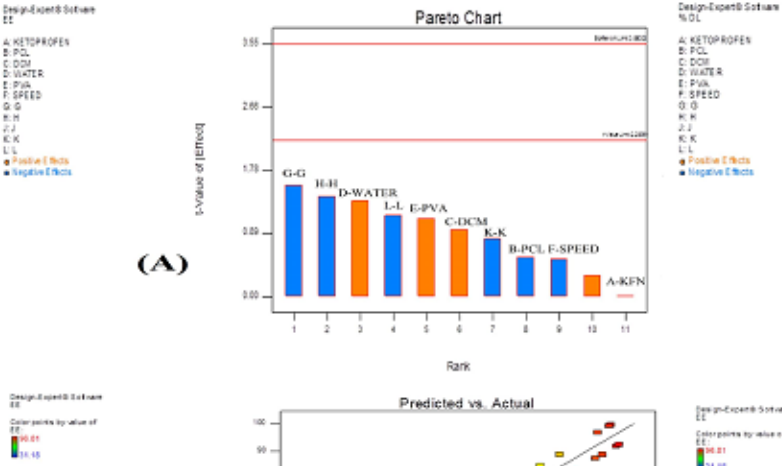

(C)
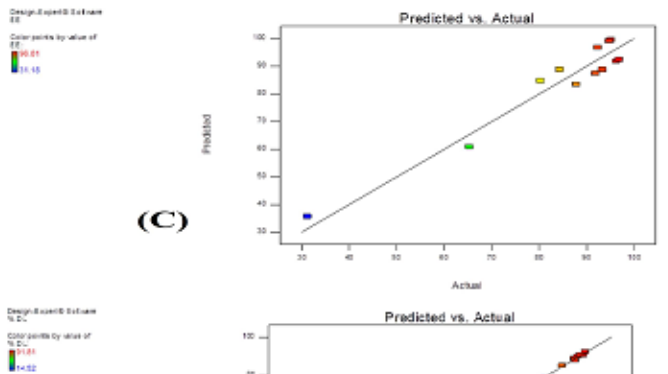

(E)

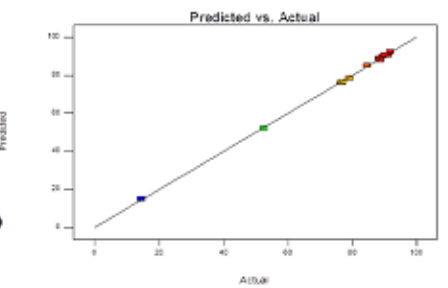

(B)

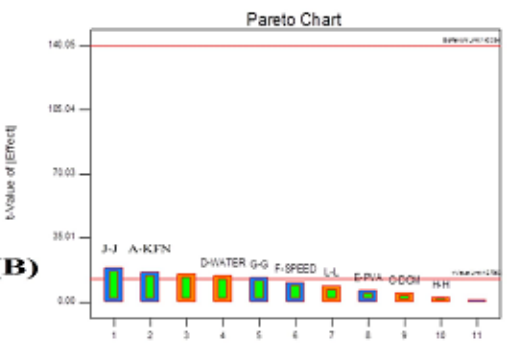

$\sin$
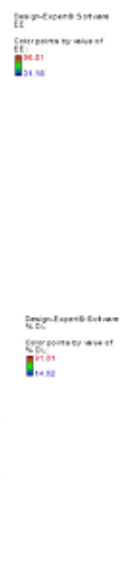
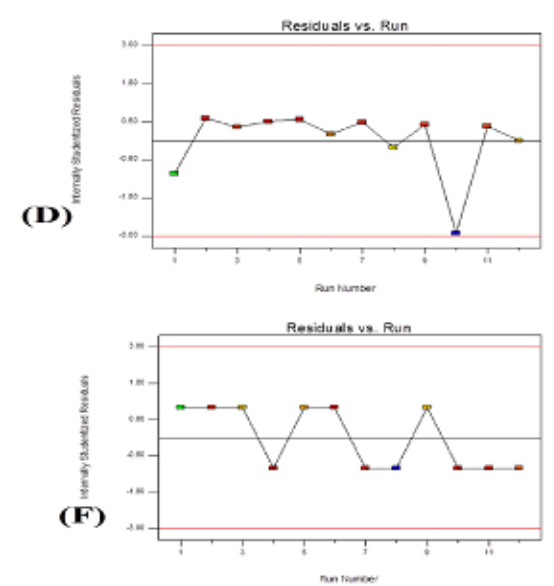

Figure 2. (A) Pareto chart of \% EE. (B) Pareto chart of \% DL. (C) Encapsulation efficiency between actual and predicted values plot. (D) Encapsulation efficiency between residuals and run plot. (E) Drug loading, between actual and predicted values plot. (F) Drug loading between residuals and run plot.

It was found that the KFN (A), PCL (B) and Speed (F) had a significant negative effect on the \% EE. The experimental, predicted, and \% prediction error values for all the experimental runs are listed in Table 5 for EE and Table 6 for the DL. Therefore, it can be concluded that the model is best suitable because of the difference between experimental and predicted value, and \% prediction error value is very low in Fig. 2 (C and $D$ ) for $E E$ and ( $E$ and F) for DL. The desirability plot indicating desirable regression ranges for optimal process variable and the overlay plot indicating the region of optimal process variables are presented in Fig. 3 ( $A$ and $B$ ) [6-7]. PBD also showed the equation of \% DL which is represented by the following equation:

$$
\mathrm{DL}=+77.00-9.03 \mathrm{~A}+8.52 \mathrm{~B}+2.65 \mathrm{C}+7.96 \mathrm{D}-3.56 \mathrm{E}-6.04 \mathrm{~F}-7.49 \mathrm{G}+1.42 \mathrm{H}-10.34 \mathrm{~J}+4.90 \mathrm{~L}
$$

The above equation 3 shows that out of eleven factors, DL increased by the factors; (A), (B), (D) and followed by the dummy factors; $(G),(J)$. Dummy factor $(J)$ and $(A)$ has higher and significant effect on drug loading in the microspheres preparation process. It was found that the factors; $(A),(E),(F),(G)$ and $(J)$ had a significant negative effect on the \% drug loading.

\section{Characterization of microspheres}

\section{Encapsulation efficiency (\% E.E)}

The EE of different experimental runs of the microspheres is reported in Table 2. The 3D response surface plots are useful in understanding about the main and interaction effects of the independent variables, whereas 2D contour plot gives a visual representation of values of the response [16]. To visualize the effect of independent variables on each response, 3D response surface plots \& 2D contour plots (Fig. 4) 
were constructed. Fig. $4 \mathrm{~B}$ shows the effects of factor $\mathrm{G}$ and $\mathrm{H}$ on the response because both factors had more significant effect as compared to others. Contour plots and surface response plots (Fig. 4A \& B) represented the increase in \% EE while (Fig. 4C \& D) represents contour plots and surface response plots of $\% D L$ respectively. Fig. 4D shows the effect of factor $J$ and $A$ on the response because both factors had more significant effect as compared to others. It was found that the KFN (A), PCL (B) and Speed (F) had a significant negative effect on the \% $\mathrm{EE}$. The \% $\mathrm{EE}$ of the microspheres was ranged from $31.18 \%$ to $96.81 \%$.

Table 5. Experimental and Predicted value of the response EE.

\begin{tabular}{|r|c|c|c|c|}
\hline Run & Experimental value & Predicted Value & Residual & \% Prediction eroor \\
\hline 1 & 65.31 & 60.86 & 4.45 & 6.81 \\
\hline 2 & 96.81 & 92.36 & 4.45 & 4.60 \\
\hline 3 & 91.86 & 87.41 & 4.45 & 4.84 \\
\hline 4 & 95.04 & 99.49 & -4.45 & -4.68 \\
\hline 5 & 96.20 & 91.75 & 4.45 & 4.62 \\
\hline 6 & 87.79 & 83.34 & 4.45 & 5.06 \\
\hline 7 & 94.66 & 99.11 & -4.45 & -4.70 \\
\hline 8 & 80.27 & 84.72 & -4.45 & -5.54 \\
\hline 9 & 93.24 & 88.79 & 4.45 & 4.77 \\
\hline 10 & 31.18 & 35.63 & -4.45 & -14.2 \\
\hline 11 & 92.34 & 96.79 & -4.45 & -4.81 \\
\hline 12 & 84.31 & 88.76 & -4.45 & -5.27 \\
\hline
\end{tabular}

Percent prediction error was calculated using the formula (experimental value - predicted value)/experimental value $\times 100$.

Table 6. Experimental and Predicted value of the response DL.

\begin{tabular}{|c|c|c|c|c|}
\hline Run & Experimental value & Predicted value & Residual & \% Prediction error \\
\hline 1 & 52.78 & 52.33 & 0.55 & 0.85 \\
\hline 2 & 88.55 & 88.00 & 0.55 & 0.62 \\
\hline 3 & 76.48 & 75.93 & 0.55 & 0.71 \\
\hline 4 & 91.81 & 92.36 & -0.55 & -0.59 \\
\hline 5 & 79.09 & 78.54 & 0.55 & 0.69 \\
\hline 6 & 91.16 & 90.61 & 0.55 & 0.60 \\
\hline 7 & 88.33 & 88.88 & -0.55 & -0.62 \\
\hline 8 & 14.52 & 15.07 & -0.55 & -3.78 \\
\hline 9 & 77.24 & 76.69 & 0.55 & 0.71 \\
\hline 10 & 90.07 & 90.62 & -0.55 & -0.61 \\
\hline 11 & 89.42 & 89.97 & -0.55 & -0.615 \\
\hline 12 & 84.53 & 85.08 & -0.55 & -0.65 \\
\hline
\end{tabular}

Percent prediction error was calculated using the formula (experimental value - predicted value)/experimental value $\times 100$. 


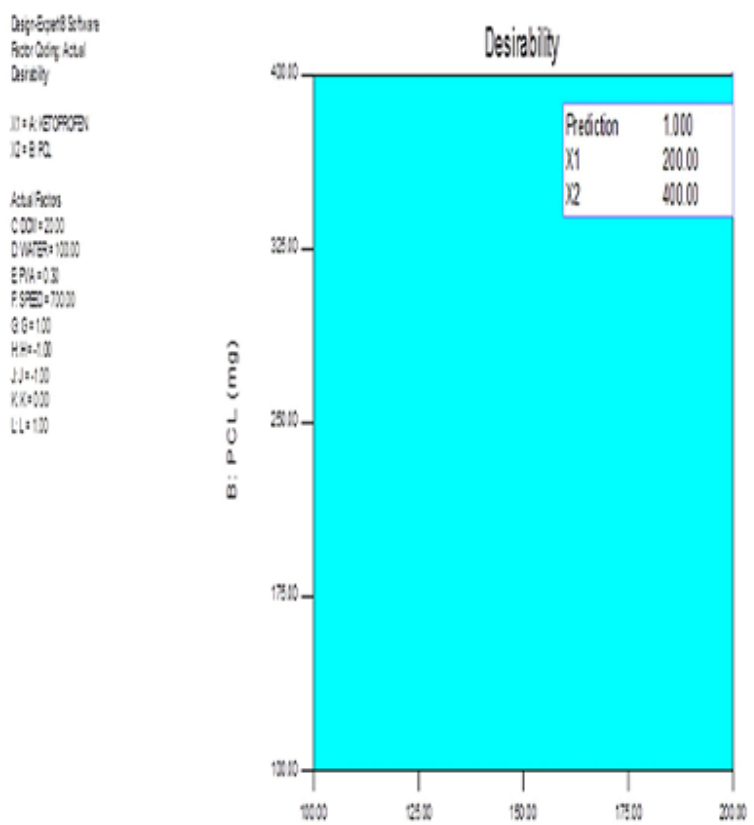

(A) ALEOPOFII $\mid$ Y

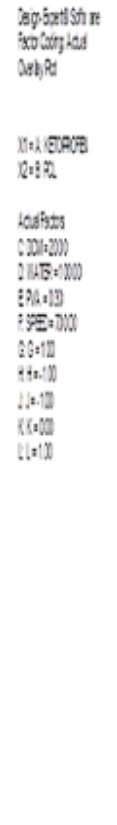

Figure 3. (A) Desirability plot. (B) Overlay plot.

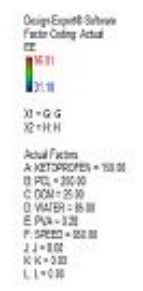

(A)
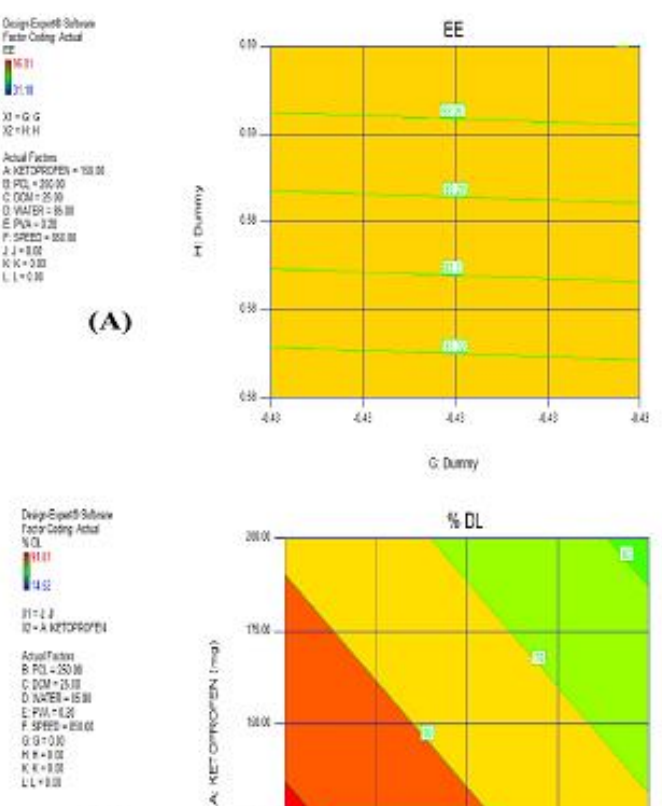

(C)
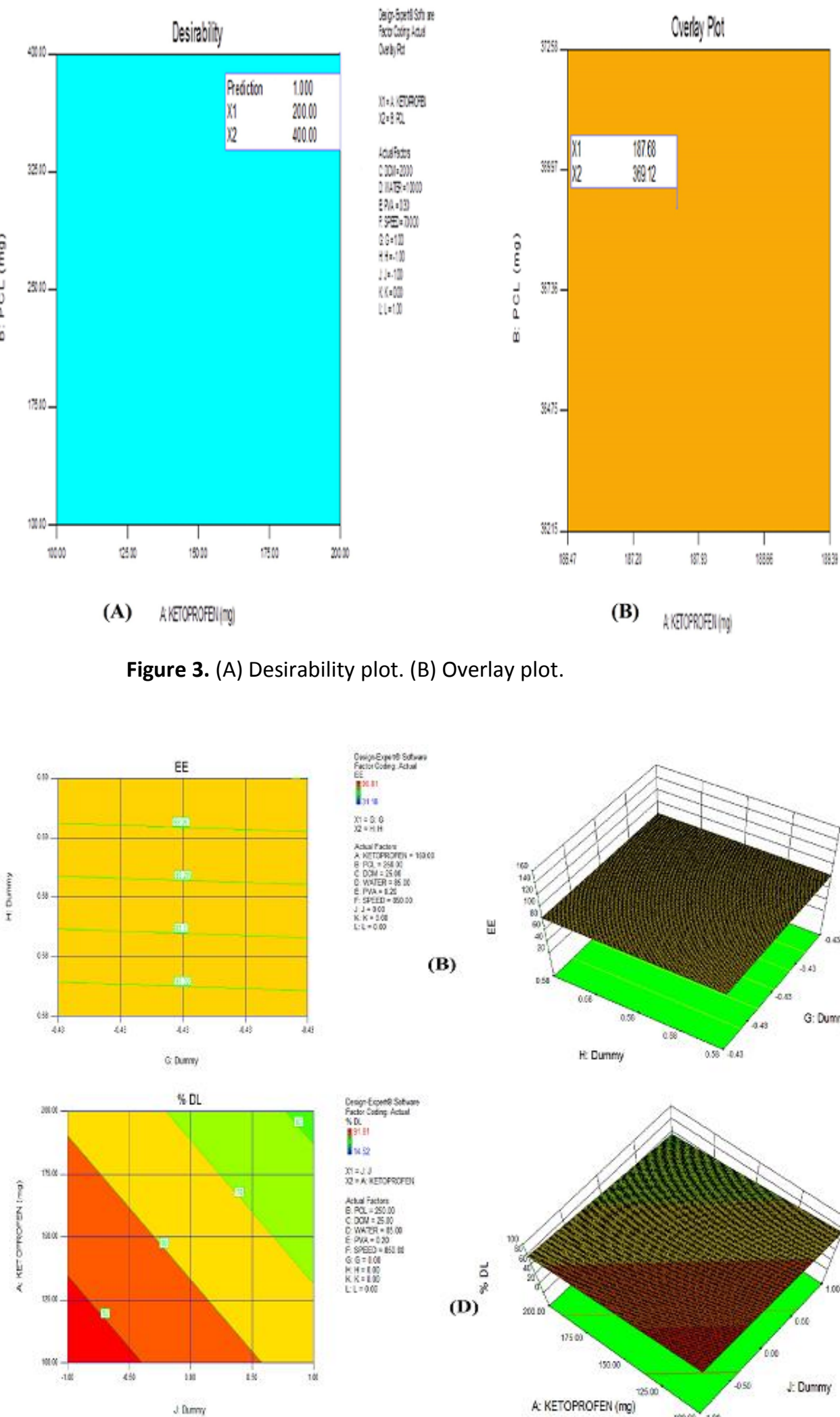

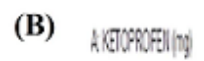
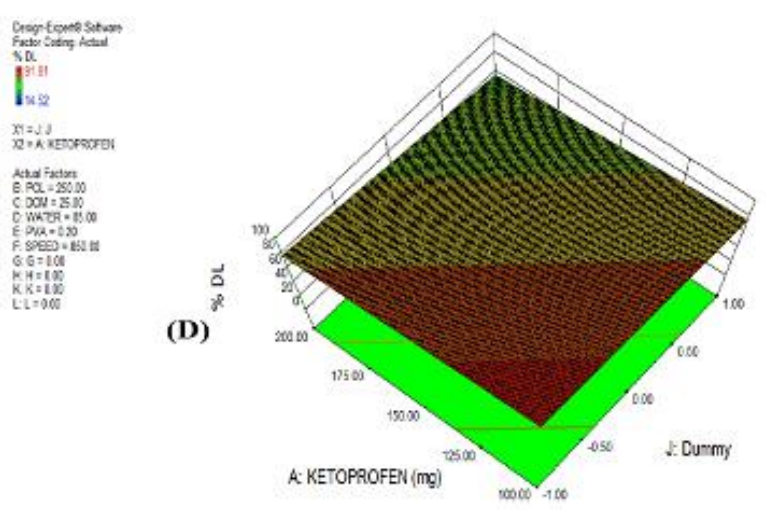

Figure 4. (A) \% EE contour plot, (B) \% EE Response surface, (C) \% DL contour plot, (D) \% DL Response surface

\section{Scanning Electron Microscopy (FE-SEM)}

Shape, size and surface morphology of the KFN loaded microspheres were examined by FE SEM. Scanning electron microphotographs of microspheres prepared in this study are shown in Fig. 5 . The size of microspheres was found to be in the range of $20 \mu \mathrm{m}$ to $293 \mu \mathrm{m}$ (Fig. 5d) and the microspheres are oval in shape with porosity and rough surface (Fig. $5 c$ and d). 

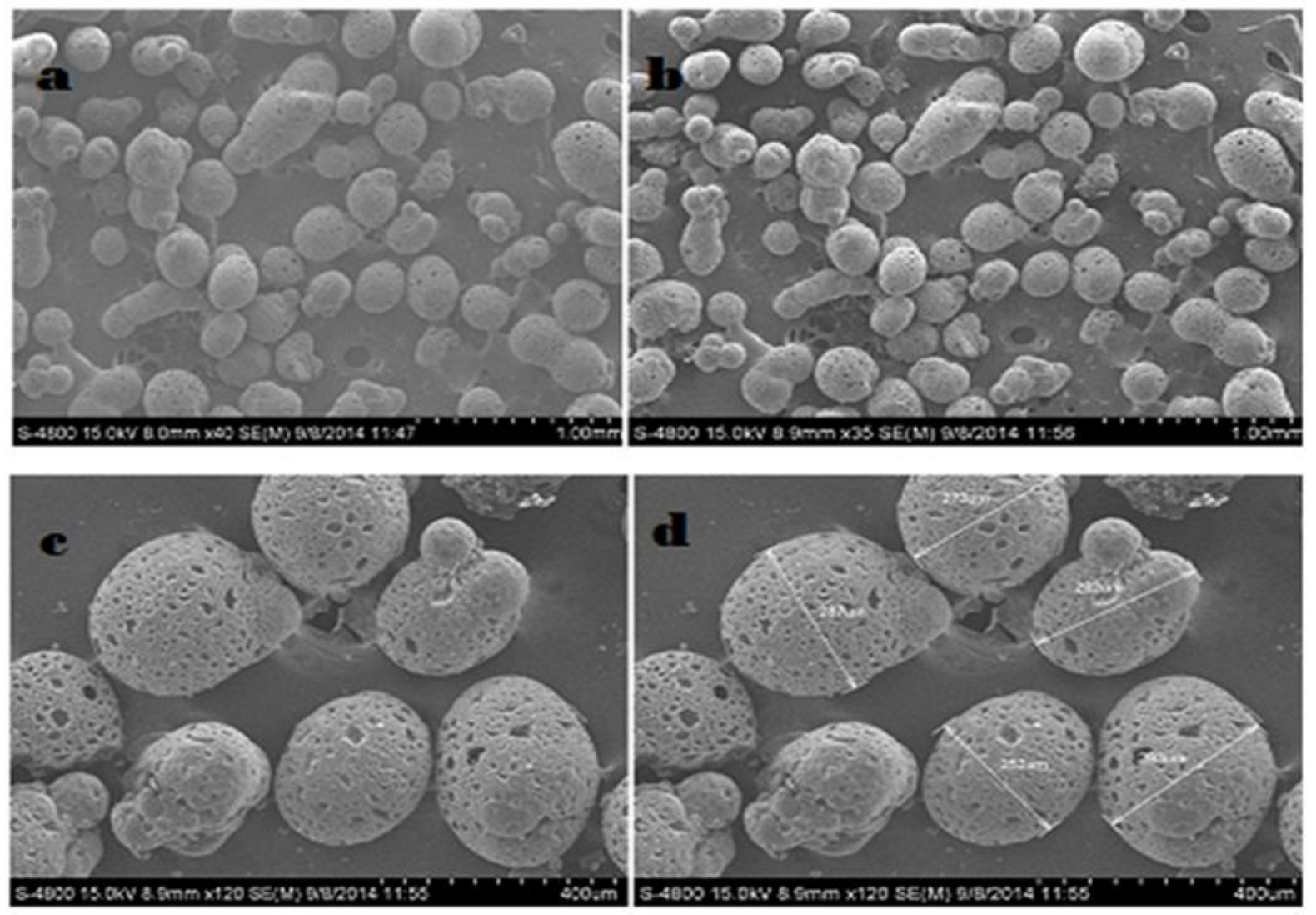

Figure 5. SEM micrographs and surface of KFN microspheres

\section{Fourier Transform infrared (FTIR) spectroscopy study}

FTIR spectra were obtained in order to analyse the prepared microspheres. Fig. 6 shows typical spectra of pure KFN, polymers and encapsulated KFN in the microspheres. In the spectrum of KFN (A), principal peaks were found at $3288 \mathrm{~cm}^{-1}$ of N-H stretching, at $1654 \mathrm{~cm}^{-1}$ of $\mathrm{C}=\mathrm{C}$ stretching, at $3055 \mathrm{~cm}-1$ attributed to $\mathrm{C}-\mathrm{H}$ stretching of the aromatic ring, at $2937 \mathrm{~cm}^{-1}$ attributed to aliphatic $\mathrm{C}-\mathrm{H}$ stretching vibrations, at $1076 \mathrm{~cm}^{-1}$ because of C-O C stretching, at $2978 \mathrm{~cm}^{-1}$ of ethoxy group stretching. In the spectra of PCL (B), principal peak at $3758 \mathrm{~cm}^{-1}$ of O-H stretching. The small peak at $2969 \mathrm{~cm}^{-1}$ corresponds to a symmetric structure vibration of the ethoxy groups, at $757 \mathrm{~cm}^{-1}$ of C-Cl stretching, at $1070 \mathrm{~cm}^{-1}$ of C-O-C stretching, at $1387 \mathrm{~cm}^{-1}$ of $\mathrm{O}-\mathrm{H}$ stretching, at $1763 \mathrm{~cm}^{-1}$ of carbonyl group stretching, These values remained very close in the FTIR spectra of optimized KFN loaded microspheres (C), indicating no existence of the interaction between the KFN and polymer.

\section{X-ray diffraction (XRD)}

The presence of numerous distinct peaks in the XRD patterns shown in Fig. 7 of KFN (A), at $2 \theta ; 5.41^{\circ}$, $12.28^{\circ}, 13.52^{\circ}, 15.34^{\circ}, 16.08^{\circ}, 16.43^{\circ}, 17.54^{\circ}$ and $18.23^{\circ}$ was present as crystalline material $88.2 \%$ and 11.8 $\%$ amorphous. There was no clear peak in the XRD patterns (B) of PCL indicate the amorphous nature of the polymer, crystalline $44.2 \%$ and amorphous $55.8 \%$. The XRD patterns of drug loaded optimize formulation (C) crystalline $58.9 \%$ and amorphous $41.1 \%$ were characterized by the absence of distinct diffraction peaks of KFN, signifying a drug amorphization. Thus, XRD analysis suggested that the degree of crystallinity of KFN was reduced in the microspheres formulation, and most of the drug distributed in the polymer at molecular level. 


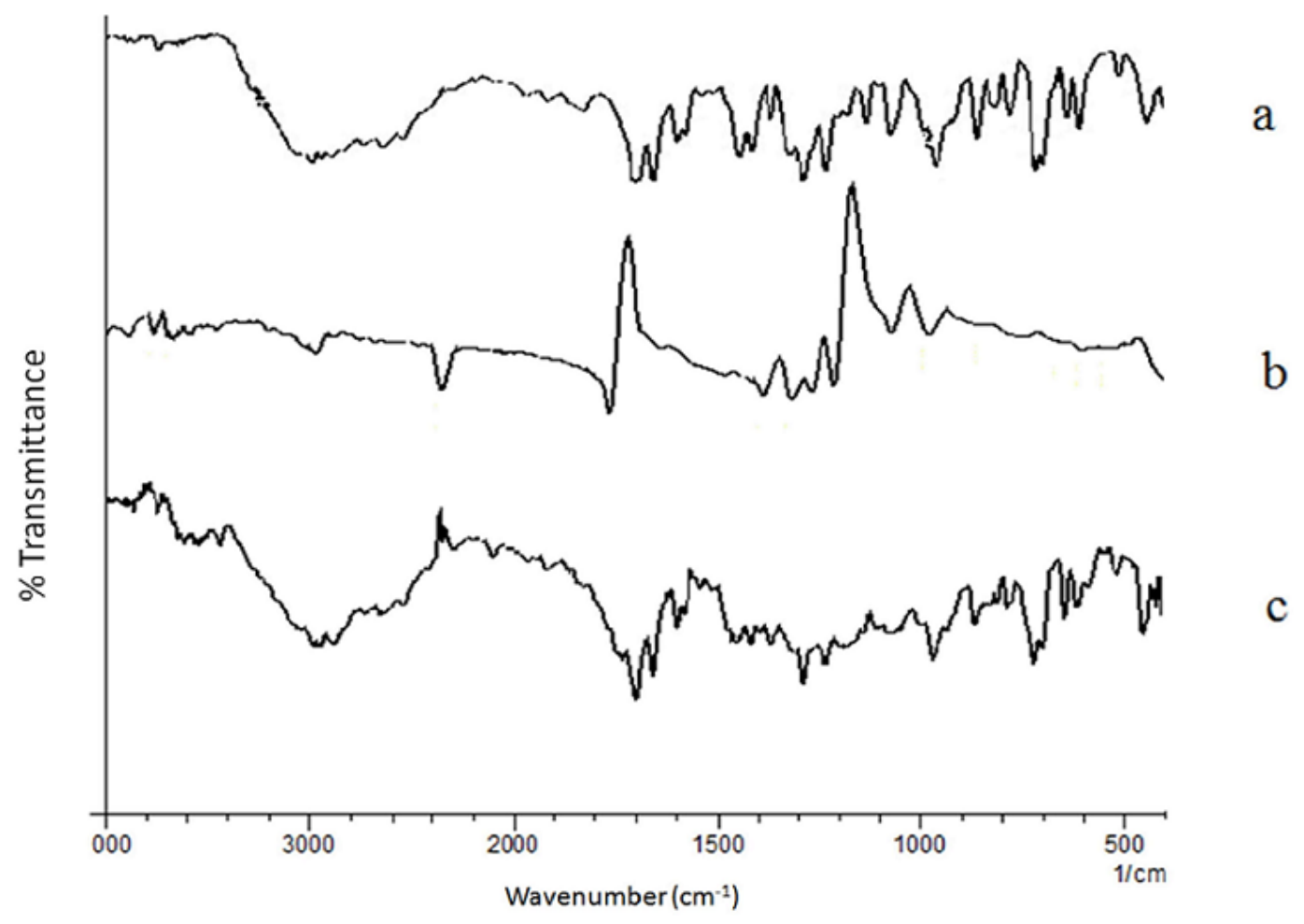

Figure 6. (a) FTIR spectra of KFN, (b) PCL, (c) Microspheres

\section{Differential Scanning Calorimetry (DSC)}

DSC was carried out to find possible interaction between the drug and polymer. This was performed for pure drug $(A)$, pure polymer $(B)$ and drug loaded microspheres $(C)$ using a differential scanning calorimeter (DSC- 60, Shimadzu). (Fig. 8) confirms that there was no interaction between drug and polymer.

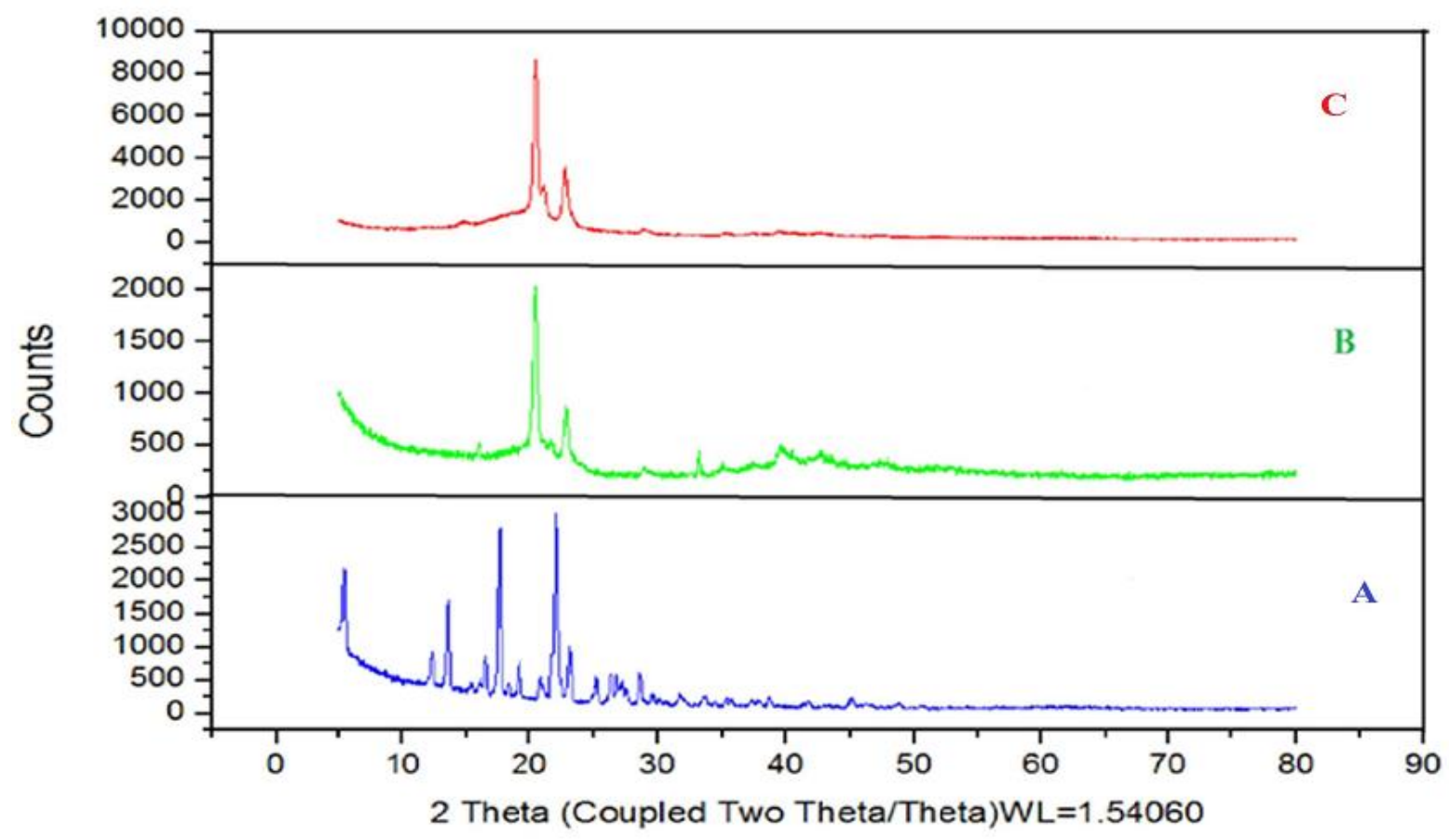

Figure 7. (A) XRD spectra of KFN, (B) PCL, (C) Microspheres 


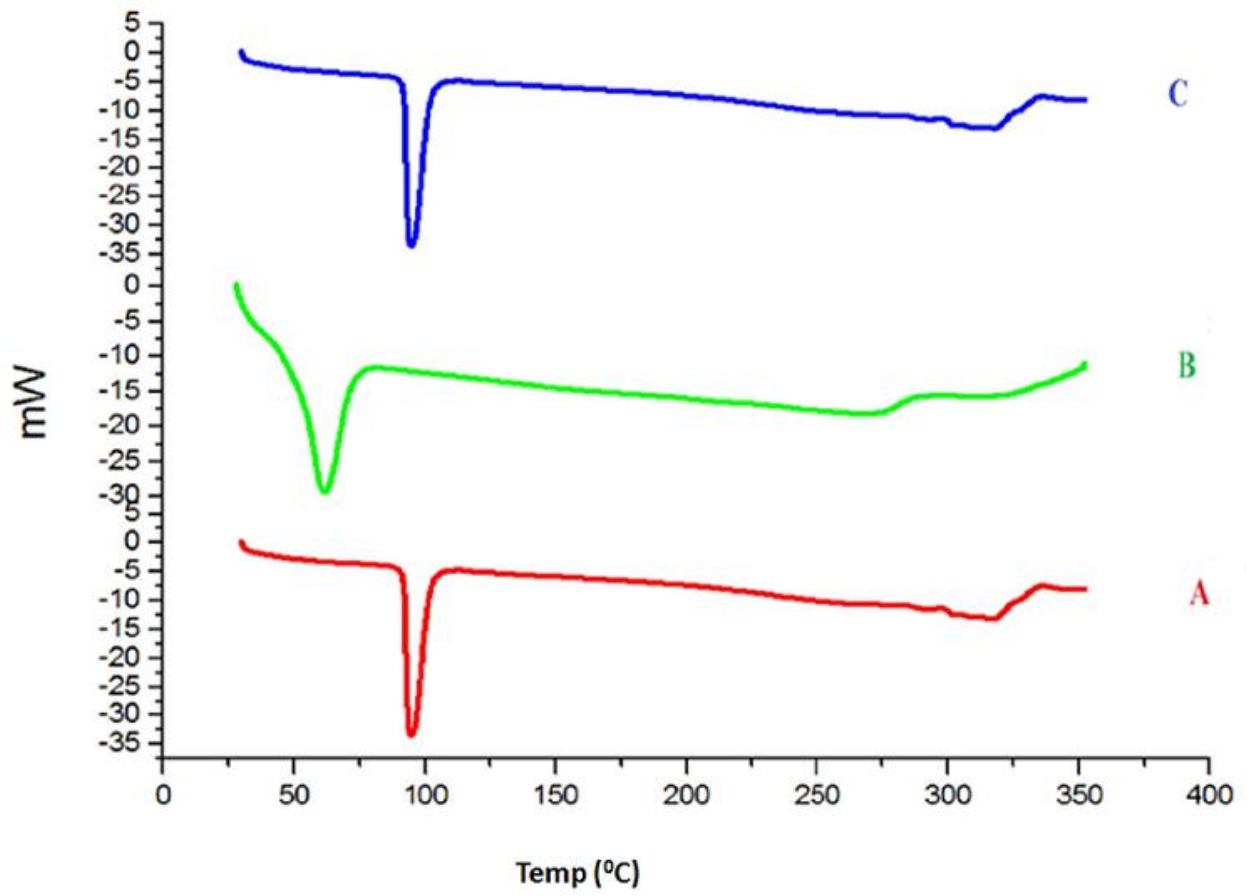

Figure 8. (A) DSC spectra of KFN, (B) PCL, (C) Microspheres

\section{In vitro drug dissolution studies}

$\mathrm{PCL}$ is water insoluble degradable polymer and able to control drug release from microspheres. Fig. 9 shows the cumulative \% drug release as a function of the dissolution time from the KFN loaded microspheres. The release of KFN was evaluated using phosphate buffer $(\mathrm{pH} \mathrm{6.8)}$ as the release media. Sustained drug release was observed in the range of $14.52-91.81 \%$ in $12 \mathrm{~h}$ study of all the experimental runs.

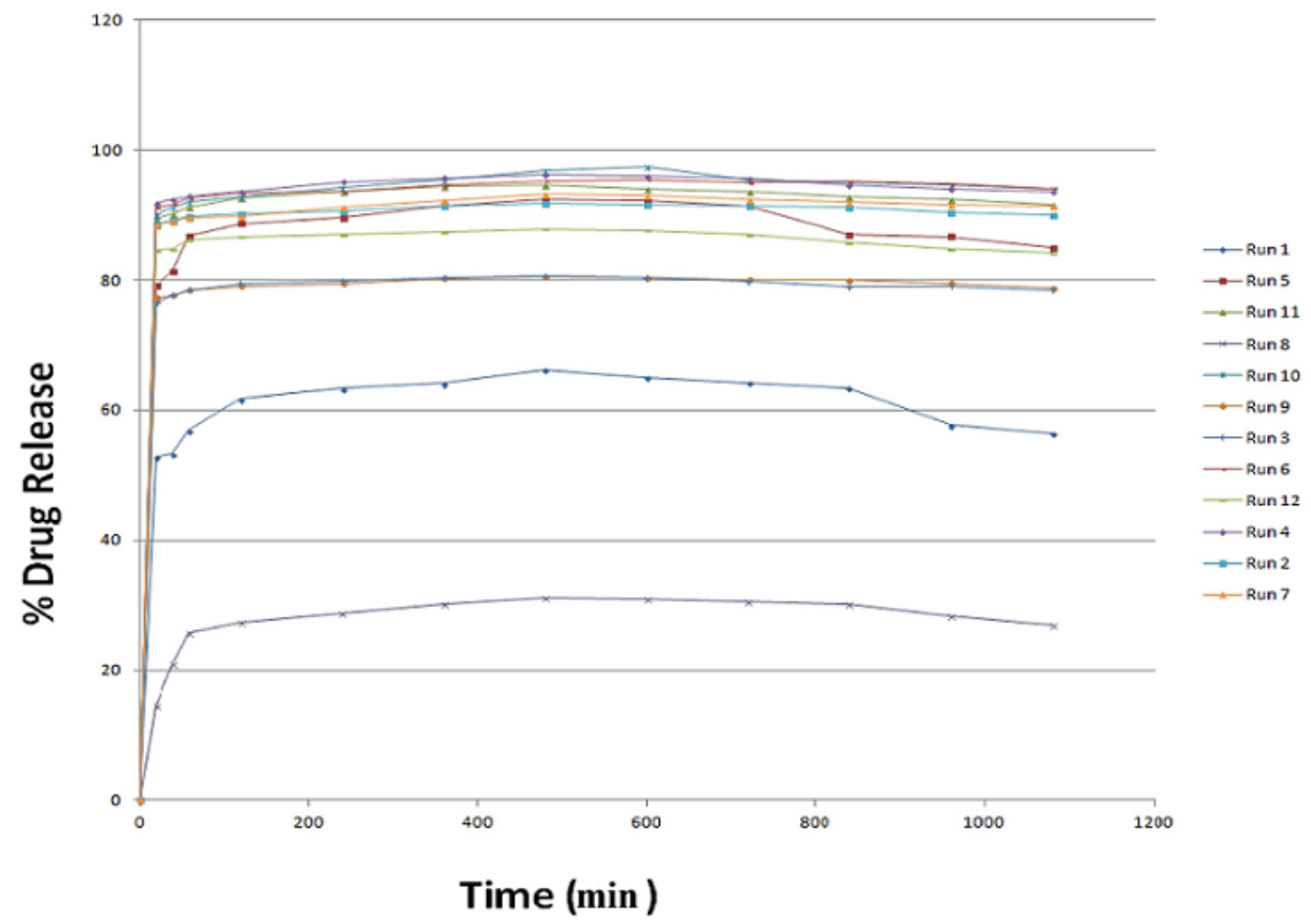

Figure 9. Cumulative \% drug release 


\section{Conclusions}

This work shows KFN loaded PCL polymeric microspheres were successfully prepared. Effects of various independent formulation or process variables and dependent variables had been screened out by employing PBD screening design. The mathematical model for the response developed using statistical analysis quantitatively describes the influence of the selected variables on the responses under study. The $\% \mathrm{EE}$ of the microspheres was ranged from $31.18 \%$ to $96.81 \%$. The size of microspheres was found to be in the range of $20 \mu \mathrm{m}$ to $293 \mu \mathrm{m}$ was confirmed by SEM analysis. The absence of drug polymer interactions was confirmed by FTIR spectroscopy and DSC. The XRPD showed the distribution of drug in the polymer at molecular level. Drug release from microspheres showed a sustained release i.e. $14.52 \%-91.81 \%$ over a period of $12 \mathrm{~h}$ in a phosphate buffer $(\mathrm{pH} 6.8)$. Microspheres prepared by such methods may represent a promising approach for efficient encapsulation and sustained drug release of KFN.

\section{Acknowledgments}

Authors are very much thankful to Technical Education Quality Improvement Program (TEQIP-II), MHRD, New Delhi for providing financial assistance to carry out this research work.

Conflict of Interest: 'All Authors are hereby declare that they have no conflict of interest'

Animal Studies: 'No animal or human studies were carried out by the authors for this article'

\section{References}

[1] M. Sandile, Khamanga, P. Natalie, Dissolut. Technol. 2 (2009) 15-22.

[2] B. Deore, H. Mahajan, U. Deore, Int. J. Chem. Tech. Res. 1(3) (2009) 634-42.

[3] J. Jeevana, G. Sunit, J. Young Pharma. 1 (2009) 24-27.

[4] G.E. Granero, C. Ramachandran, G.L. Amidon, Pharmazie 61 (2006) 673-676.

[5] Y. Tomofumi, O. Hiracu, M. Yoswharu, Yakugaku Zashi 121(3) (2001) 239-245.

[6] R.K. Deshmukh, J.B. Naik, Mat. Sci. Eng. C 36(C) (2014)320-328.

[7] R.K. Deshmukh, J.B. Naik, J. Pharm. Innov. 8 (2013) 276-287.

[8] P. Wang, Z.W. Wang, Z.C. Wu, Chem. Eng. J. 193 (2012) 50-58.

[9] R.S. Liu, Y.J. Tang, Bioresour. Technol. 101 (2010) 3139-3146.

[10] S. El-Malah Nazzal, Int. J. Pharm. 309 (2006) 163-170.

[11] S.B. Imandi, V.V.R. Bandaru, S.R. Somalanka, S.R. Bandaru, H.R. Garapati, Bioresour. Technol. 99 (2008) 4445-4450.

[12] R.L. Plackett, J.P. Burman, Biometrika 33 (1946) 305-325.

[13] J. Murray. Statistical Experimental Design, Data Analysis and Nonlinear Optimisation, John Wiley and Sons, New York, 1994.

[14] J.B. Naik, A.B. Lokhande, S. Mishra, R.D. Kulkarni, Int. J.Pharma Biosci. 3(4) (2012) 573-590.

[15] Indian Pharmacopoeia Commission Ghaziabad, Indian Pharmacopoeia (2007) pp-480.

[16] A.K. Nayak, D. Pal, J. Pradhan, M.S. Hasnain, Int. J. Biol. Micromol. 54 (2013) 144-154.

C2015 by the authors; licensee IAPC, Zagreb, Croatia. This article is an open-access article distributed under the terms and conditions of the Creative Commons Attribution license (http://creativecommons.org/licenses/by/3.0/) (cc)) EY 